\title{
Contribution of Prefabricated Constructions to Reduce the Risk of Project Management
}

\author{
Ahmed Mohammed Teen Ahmed ${ }^{1}$, Prof. Dr. Eng. Ana Maria Gramescu² \\ ${ }^{1}$ Doctoral School of Applied Sciences / Ovidius University of Constanta \\ Unirii street, Constanta, Romania \\ muhammedteen@yahoo.com; sdaplicate@univ-ovidius.ro \\ ${ }^{2}$ Prof. Dr. Eng. Doctoral School of Applied Sciences / Ovidius University of Constanta \\ Unirii Street, Constanta, Romania
}

\begin{abstract}
Project risk management focuses on key aspects of time, cost, human resources, safety and security, quality as well as environmental challenges, and the construction pattern is an important part of the problem. With the tremendous development in the field of construction and with the increasing need to complete the projects as quickly and as possible, the importance of the use of prefabrication technology to solve many of the problems facing the construction sector. Prefabricated concrete is no longer restricted to the industrial construction sector and is now used on a single scale in all construction areas such as housing and commercial buildings. The economic feasibility of the use of prefabricated concrete being in increasing the overall performance factors of the projects from reducing time, reducing cost and applying quality standards. With the development of additives for concrete mixtures, the quality of prefabricated concrete can be improved by improving the properties of concrete in terms of resistance, increasing thermal insulation and reducing stress applied on foundations through the use of foamed concrete and high resistance concrete. Improving the time of projects is important for the early use of facilities in order to expedite the recovery of the project's revenue value, use of prefabricated construction maybe reduce the time of implementation $10 \%$ or more. The ease of finishing works for prefabricated concrete blocks is quick and high quality due to the quality control inside the factory, despite some disadvantages related to the prefabricated concrete manufacturing in terms of the high cost of equipment and the need for large transport machineries. Its use with great economic feasibility contributes to the development of construction sectors.
\end{abstract}

Keywords: prefabricated construction, cost management, quality, environmental reality, time management, insulation.

\section{Introduction}

With the technological development in the field of construction it has become necessary to use more efficient techniques in construction projects which lead to more efficiency in time, cost, and quality in addition to increase the performance of human resources and reduce the accidents in site of projects. One of the most important factors to improve projects management is a time of implementation, the "main aim of using prefabricated constructions is to obtain efficient building components and specialized equipment to reduce the cost and the time of implementation"[1]. "Prefabricated constructions are stilled a construction method in USA and another European countries" [2]. The choice of pattern for choosing the type of building used depends on several factors that affect the economic, social and environmental feasibility study.

\section{Prefabricated components contribution to improve the management of construction projects 2.1. Prefabricated walls}

Precast walls are one of the most important structural elements that contribute significantly to improving project performance, The importance of prefabricated walls represent by improve the consumption of electric power greatly through several scientific methods, including the use of foam concrete, which lead to the formation of air voids to help increase thermal insulation in addition to increasing the acoustic insulation. The walls represent the highest percentage of dead loads placed on load-bearing structural elements. It is therefore possible to take advantage of modern technologies to reduce dead loads by using lightweight walls and reduce the quantity of reinforcement and quality of concrete mass in foundation and another construction element like a columns and beams. 


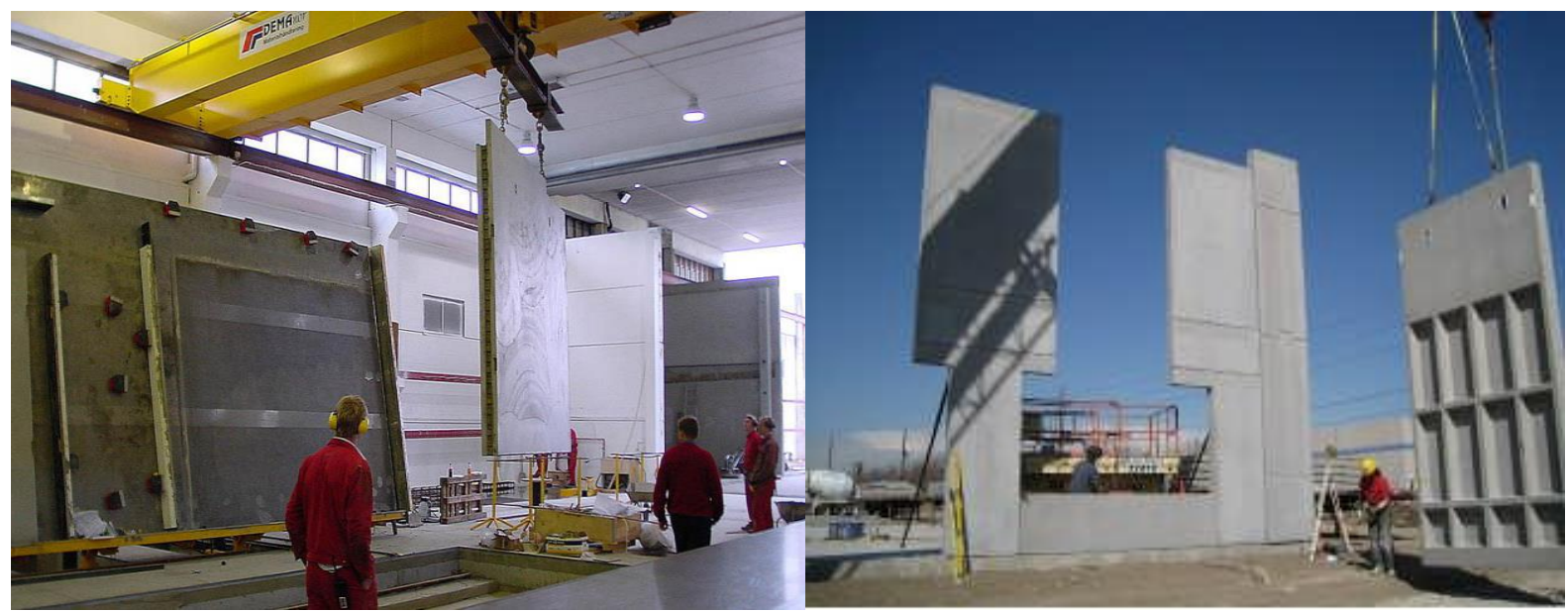

Fig. 1: Prefabricated wall.

\subsection{Prefabricated slabs}

The use of prefabricated concrete slabs in the construction provides many great features in terms of ease of installation. The pouring of slabs by using traditional methods requires a lot of effort and time and often leads to serious accidents due to the existence of large work spaces with high altitudes, in addition to the plenty of manpower. Prefabricated hollow concrete slabs provide high spaces that may exceed $15 \mathrm{~m}$ and achieve of high thermal insulation and acoustic insulation, "in case of using pre-stressed hollow slab we can reach to $24 \mathrm{~m}$ span"[3].

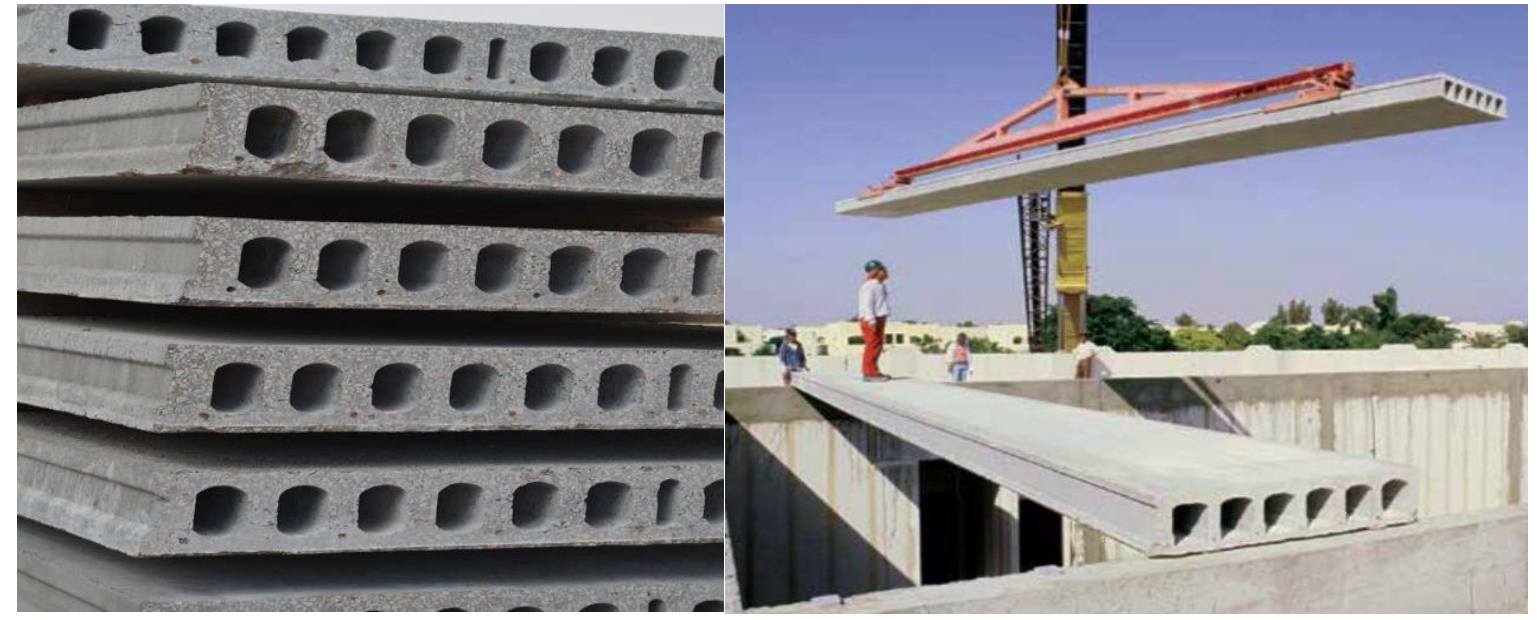

Fig. 2: Prefabricated hollow slab.

\subsection{Prefabricated beams and columns}

The beams and columns are the most important structural elements and need to increase their quality by using good materials and a good method of curing like a curing by power of steams. It is very important that the connection between the columns and beams in a style that ensures high stability of the structure as well as increase the shear resistance of the members located in a connection area between the beams and columns. The use of pre-stress technology for concrete members, especially the beams, provides the addition of large spaces that may lead to the realization of architectural requirements that need to provide larger spaces such as conference halls, industrial structures, workshops and warehouses. Pre-stressed beam has a high resistant against shear moments diagonal tension [4].

\subsection{Equations}


There are two types of precast stairs first be with landing, second be separated but the second type is most common. The process of pouring the stairs requires skilled labor, especially reinforcing works and adjusting the measurements so the so the use of precast stairs leads to more advantages include:

- Easy installation

- High quality surface finish

- The measurements are consistent for all drawer details

- High resistance to stresses
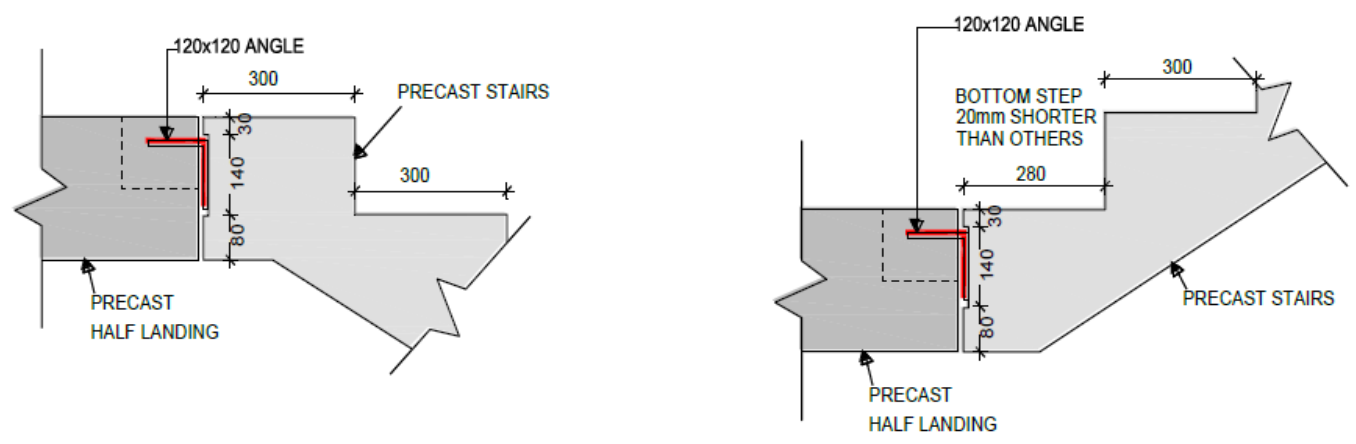

Fig. 3: Connection between slab and stairs [5].

\section{Contribution of prefabricated constructions to reduce the risk management}

Risk in projects is an event that is expected to occur in the project and may have a negative or potentially positive impact. Risk management aims to reduce the probability and impact of negative events and increase the probability and impact of positive events [6]. The risks related to the project are divided into several sections, including administrative aspects, financing aspects of the project, or related to the technical aspects, like the inaccuracy of the feasibility study and incorrect in schedule of tasks.in this study discussion the technical aspects that lead to increase the accuracy of feasibility study and increase the certainty of estimation calculation, prefabricated construction help us to improve and optimize the feasibility study and reduce the expected risks which affect the success of the project, the most important contributions of precast constructions are:

\subsection{Reduce the risk of incorrect quantities}

One of the most important challenges engineers find during the economic feasibility study is the correct and accurate estimation of the quantities needed to achieve the project scope through the identification of tasks and their quantities (by using work breakdown structure WBS), and with the complexity of the large quantity of tasks and there ramifications, especially in large projects that have a many tasks lead to incorrect calculation related to feasibility study. By using prefabricated construction we can get a perfect solution through the clarity of quantities and prices that can be obtained through technical and commercial offers of precast concrete factories.

\subsection{Reduce the risks of incorrect human resources calculation}

Construction works require much manpower in all areas of project implementation. The large number of workers generates many problems, especially through the breakdown structure of responsibilities that determines a lot of work teams and according to the main specialties in the project. The large number of work teams in the projects lead to interference in the workspaces as well as interference in the responsibilities, which in turn lead to conflicts between teams and therefore are real risks to the management of the project. The usage of manpower reduced $15-20 \%$ in case of use prefabricated construction [7].

\subsection{Reduce the risks of execution budget}

The calculation of costs in construction projects is of great importance to companies and investment institutions, since the economic feasibility accounts for projects, especially the economic accounts, which represent the amount of profits and revenue that should be obtained after investment, which are closely related to the amount of budget provided for 
construction, maintenance and operation. Each project determines the senior management of the institutions the amount of the contingency budget is often between $5 \%$ to $10 \%$ of the value of the project and give the powers to the project manager the possibility of spending of this budget or may in some cases not to give the project manager powers to spend the emergency budget (Figure 4), and this spending depends to the economic conditions of the company, according to the strategic management of the company's projects or institution the risks increase in case of work breakdown structures includes many tasks and activities that lead to uncertainty of total cost estimated especially in case of using traditional style of construction. Prefabricated construction leads to reduce the risks of project because of we can get a high accuracy to determine a baseline cost. The waste in construction materials for the use of on-site casting may reach $10 \%$ of the total quantity because of the lack of proper storage of materials and the non-handling of these materials during the course of work correctly. Use of waste materials lead to reduce the cost of concrete $12 \%$ [8].

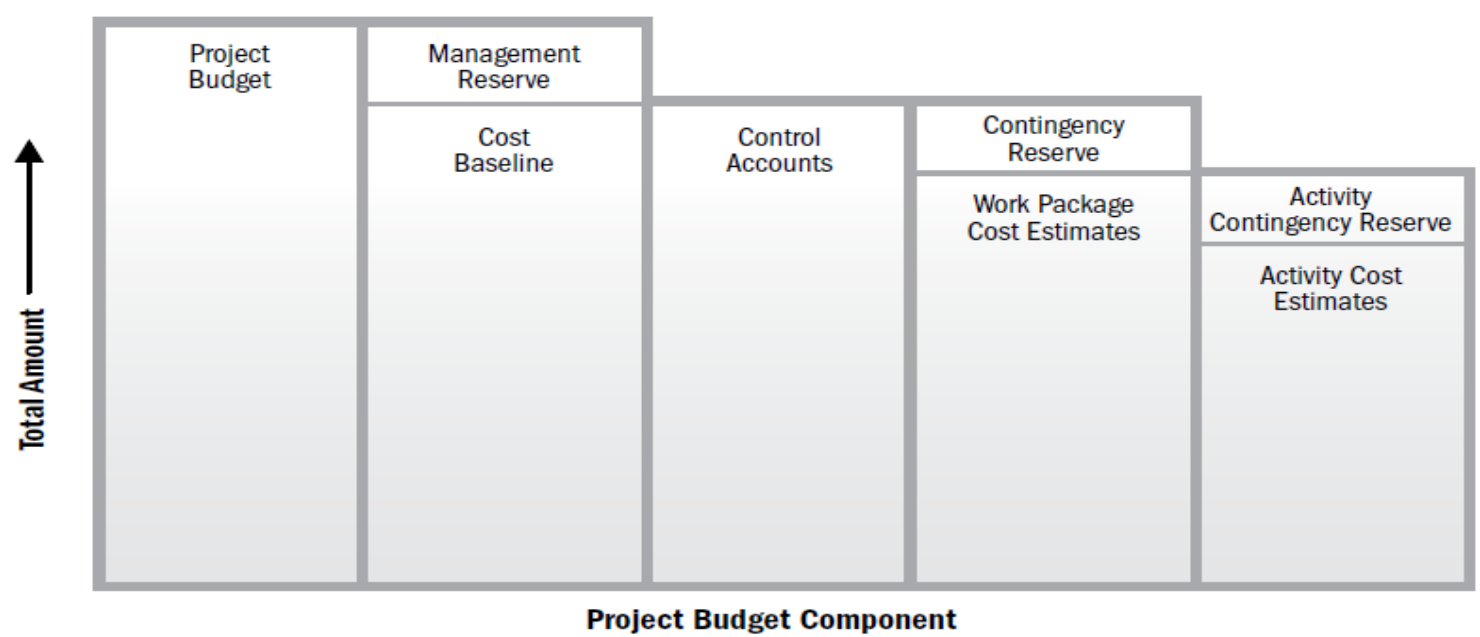

Fig. 4: Project budget components [9].

\subsection{Reduce the risk of tasks implementation schedule}

The management of project time depends heavily on the type of project and the techniques used in it, through which the time of each activity and task is placed. The use of traditional construction techniques makes it important to think about allocate a reserve time for activities because it requires many machinery, equipment and manpower to complete those projects. Prefabricated construction reduces the time of implementation because many factors effected on this type of construction:

- Reduce the scaffoldings

- Reduce the warehouses construction

- Reduce the machinery and reduce time of transport.

- Reduce the time of daily training of worker especially in high location.

- Reduce the time of waste elimination.

- Reduce the time of curing.

- No need to wait the time of concrete hardening.

The early completion of projects reduces the possibility of fines on executing companies as a penalty condition such as the delivery of residential complexes to customers or the delivery of a production plant or commercial building, In addition, the delay in the completion of projects leads to increase the cost of the project by the following:

$\circ$ Increase direct expenditure (manpower, machinery, transport).

- Increase indirect expenditure (insurance, fees, taxes and other expenses).

In general prefabrication construction reduces of implementation time 20\% [10].

\subsection{Reduce the risks of accidents}


Accidents in construction projects are usually caused by a number of labors, including labor intervenes, intervenes of work teams, increase in scaffolding, etc. The most common activities and tasks leading to accidents are reinforced concrete works for columns, beams, walls and slabs (include reinforcing works, shuttering works and pouring works), Pre-fabrication may be highly risky unless these risks are identified and actions and precautions are taken during implementation[11]. Most significant potential risks that lead to accidents during the installation of prefabricated concrete elements:

$\circ$ Non-arrival of concrete prefabricated concrete elements to design strength (Urgent in the erection process).

$\circ$ The use of lifting equipment does not match the nature of the real weights of precast concrete elements.

- Failure to develop an appropriate plan for the installation work in which the priorities of the work are determined (Pre-fabricated structural elements shall be installed in a sequential method in a manner that preserves the equilibrium of the structure).

- Manufacturing problems (mistakes) for prefabricated structural elements.

- Loss of perfect warehouses inside the project.

The largest proportion of accidents at the site is caused by workers (Table1). Therefore, reducing the percentage of workers at the site leads to a significant reduction in accidents. During 7 years ago accidents in the projects sites reduced 65\% [12].

Table 1: General factors of accidents at site work [13].

\begin{tabular}{|c|c|c|}
\hline General factors of accidents & Frequency & percent \\
\hline Workers & 45 & 46.3 \\
\hline Equipment and Machinery & 13 & 18.6 \\
\hline Different procedure & 9 & 12.9 \\
\hline Site work & 3 & 4.3 \\
\hline Total & 70 & 100 \\
\hline
\end{tabular}

\subsection{Reduce risks of low quality}

It is certain that many of the problems that may lead to the loss or reduction of quality in the construction projects are reinforced concrete works, which are often experienced by engineers during the implementation in a traditional method of construction. Most important mistakes occur during the implementation and leads to reduce quality are the following:

- Loss of accurate monitoring for all project activities

- Corrosion of reinforcing steel because of outside humidity

- Mistakes occurred during the pouring process.

- Incorrect curing

- Incorrect finishing works

- Using of bad and old shutter in pouring process.

For these reasons, the prefabricated construction technology is a practical solution to solve the problems of implementation and improve the quality of the work done.in case of using prefabricated construction may be obtains high quality because of following:

- Correct factory monitoring

- Good quality curing (by using steam and another ways)

- Using of a good quality of reinforcing steel

- Using of a good quality of shutters.

- Perfect surfacing works (using of special equipment)

- Good vibration after pouring process

It is also possible to add improvements to the quality of prefabricated concrete depending on the type of use. The use of chemical additives with the mixture of reinforced concrete to increase the strength of bending moment or the shear forces in order to increase the tolerance of beam spaces exceeds than $24 \mathrm{~m}$ length or reduce the weight of walls, partitions and panels by using foam concrete or another methods to improve the insulation of buildings (acoustic or thermal).

\section{Effect of prefabricated constructions on sustainability constructions reality}


Sustainability is a term mean that develop the present construction without effect on a future environment [14], Eco-friendly using materials and technology that have a minimum effect on the environment [15] Environmental determinants are of great importance in identifying projects and industries, especially with climate change and global warming, the choice of building patterns is specific to environmental determinants and specifications. Pollution and energy consumption are in most cases the result of the extraction of raw materials as well as the transport of raw materials from the places of extraction to the plant. When we are using prefabricated construction elements 20 and $50 \%$ of materials may be saved by using this style more than traditional style [16]. Carbon emissions during the prefabricated manufacturing life cycle stages are less than the amount of carbon emissions in the concrete cast in-situ (Figure 5).

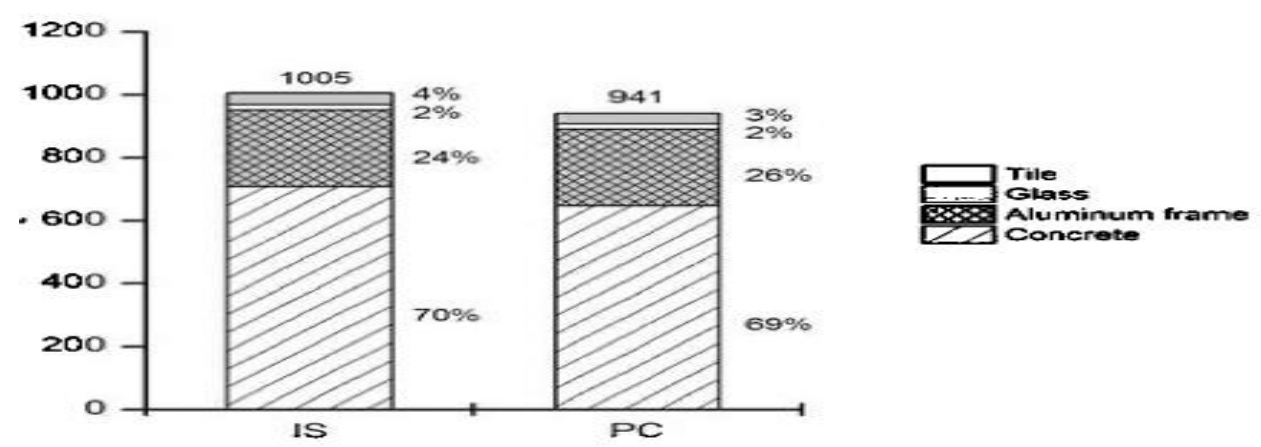

Fig. 5: Carbon emissions cast-in-situ IS and precast PC [17].

\section{Comparison the results(traditional vs. prefabricated construction)}

Table 2: Traditional vs. prefabricated construction.

\begin{tabular}{|c|c|c|c|}
\hline & Potential risks & Traditional construction & Prefabricated construction \\
\hline 1 & Completion time & $\begin{array}{l}\text { High risk of completion time due } \\
\text { to the large number of tasks and } \\
\text { activities }\end{array}$ & $\begin{array}{l}\text { Low risk of completion time due to } \\
\text { the few number of tasks and activities, } \\
<20 \% \text { or more }\end{array}$ \\
\hline 2 & Project budget & $\begin{array}{l}\text { Multiple activities lead to } \\
\text { increased direct and indirect } \\
\text { expenditures }\end{array}$ & $\begin{array}{l}\text { Specific events and predefined price } \\
\text { reduces the risk of exceeding the } \\
\text { budget limits }\end{array}$ \\
\hline 3 & Poor quality & $\begin{array}{l}\text { Difficulty controlling and } \\
\text { monitoring the quality in case of } \\
\text { site works }\end{array}$ & $\begin{array}{l}\text { High quality, opportunity of increase } \\
\text { dimensions and specification, use of a } \\
\text { additives, steam curing, ease of } \\
\text { finishing works. }\end{array}$ \\
\hline 4 & Increase Manpower & $\begin{array}{l}\text { Difficulty managing manpower } \\
\text { (the need for many workers) }\end{array}$ & Manpower required $<15-20 \%$ \\
\hline 5 & Potential accidents & $\begin{array}{l}\text { Increase manpower leads to } \\
\text { increase accidents (The } \\
\text { proportion of accidents due to } \\
\text { manpower represents } 46.3 \% \text { of } \\
\text { the total accident rate). }\end{array}$ & $\begin{array}{l}\text { A high probability of reducing } \\
\text { accidents due to reduce of manpower }\end{array}$ \\
\hline 6 & Environment & $\begin{array}{l}\text { Do not lead to a sustainable } \\
\text { environment (high pollution due } \\
\text { to construction waste). }\end{array}$ & $\begin{array}{l}\text { One of the building patterns that lead } \\
\text { to sustainable construction. }\end{array}$ \\
\hline
\end{tabular}

\section{Conclusion}


Precast concrete can be a practical solution for future construction in many construction sectors through economic and environmental feasibility to reduce risks and hazards, which is a priority in the choice of construction style. The economic cost of prefabricated construction provides a total cost of between 5-10\% compared to traditional construction by utilizing the waste material which provides $12 \%$ of the total amount of concrete produced, In addition to reducing many direct and indirect expenses of machinery, equipment, workers and stores in addition to the accuracy of the preliminary calculations of the estimated costs, which in turn improve the accuracy of the feasibility study. Reducing the time of projects is one of the most important priorities of project management, which is one of the most important challenges for companies and investment institutions. One of the keys to success is through the use of prefabrication technology through reduces the completion time by $10 \%$ or more. Because of the growing environmental problems that construction sector is a large part of this problems, prefabricated construction is one of the solutions to reach the sustainable environment by reducing carbon emissions. The use of prefabricated concrete reduces accidents significantly by reducing the number of workers inside the project site because accident records indicate that most accidents occur because of people and then equipment. It is possible to improve the quality of various structural elements through the using of modern technologies, including the use of foam concrete in the external walls and internal partitions, which reduces the dead loads applied to the structure, as well as increase the work of thermal insulation to reduce the energy consumption in addition to reduces acoustic insulation and reduces the noise, we can use of prefabricated beam reaches to $24 \mathrm{~m}$ length by adding chemical additives.

\section{References}

[1] M. Anderson and P. Anderson, Prefab prototypes Site-specific design for offsite construction, Princeton Architectural Press, New York, 2007.

[2] R. Kumar, M. Patterson, "A case study on use of precast technology for construction of high-rise Buildings," NTPC Global Energy Technology Summit (GETS), At New Delhi, 2016, Volume III.

[3] S. Ghannam, "Comparison of precast construction in developed and developing countries," in Global Congress and expoon/materials science\&nano science, Dubai, 2016.

[4] A. F. Izzet, A. A. Abdulhameed, Prestressed concrete: a fundamental approach ACI 318-11 code philosophy and stresses limitations [Online]. Available: https://www.researchgate.net/profile/Ali_Abdulhameed/publication/316494450_Prestressed_Concrete_A_Fundame ntal_Approach_ACI_31811_Code_Philosophy_Stresses_Limitations/links/590115e0a6fdcc8ed50eeb06/Prestressed -Concrete-A-Fundamental-Approach-ACI-318-11-Code-Philosophy-Stresses-Limitations.pdf

[5] KEEGAN PRECAST LTD, Stairs and landing-product information [Online]. Available: http://www.keeganprecast.com/docs/Stairs--Landings-Product-Information.pdf

[6] Project management institute, A guide to the project management body knowledge PMBOK, $5^{\text {th }}$ edition, PMI, 2013.

[7] A. Kadir, W. P. Lee, M. S. Jaafar, A. A. A. Ali, "Construction performance comparison between conventional and industrialised building systems in Malaysia", International Journal of building pathology and adaptation, 2006, vol. 24, no. 5, pp. 412-424.

[8] I. Nahmens, L. H. Ikuma, "Effects of Lean Construction on Sustainability of Modular Homebuilding," Journal of Architectural Engineering, ASCE, 2012, vol. 18, no. 2, pp. 155-164.

[9] Project management institute, A guide to the project management body knowledge PMBOK, $6^{\text {th }}$ edition, PMI, 2017.

[10] L. Jaillon, C. S. Poon, "Advantage and Limitation of Precast Concrete Construction in High-rise Buildings: Hong Kong case studies," in CIB world Building Congress, CIB, 2007, pp. 2504-2514.

[11] C. Kirubakaran, "Safety in Precast Erection," The masterbuilder, vol. June 2015, pp.84-88, 2015.

[12] Architectural Cladding Association, Sustainability and precast concrete cladding, British Precast, Leicester, 2009.

[13] M. F. M. Zaki, W. Z. A. W. Muhamad , A. Ayob , M. Q. Suhaimi, "Safety in IBS Construction", Global Journal of Pure and Applied Mathematics, vol. 12, no. 3, pp. 2367-2373, 2016.

[14] National Precast Concrete Association Australia. (2015) Sustainability [Online]. Available: https://nationalprecast.com.au/sustainability/

[15] R. Sparks. (2016, August 8) Is Precast Concrete Environmentally Friendly [Online]. Available: https://www.columbiaprecastproducts.com/blog/is-precast-concrete-environmentally-friendly/

[16] WRAP. (2019) Waste Reduction Potential of Precast concrete Manufactured Offsite [Online]. Available: http://www.wrap.org.uk/sites/files/wrap/Pre-cast\%20concrete\%20-\%20Full\%20case\%20study1.pdf 
[17] Y. H. Dong, L. Jaillon, C. S. Poon, "Life cycle assessment of precast and cast-isitconstruction," in Sustainable Built Environment, Regional Conference, SBE, Zurich, 2016, pp.426-429. 